Check for updates

Cite this: RSC Adv., 2019, 9, 636

Received 15th October 2018 Accepted 29th November 2018

DOI: $10.1039 / c 8 r a 08543 a$

rsc.li/rsc-advances

\section{Effect of networked hybridized nanoparticle reinforcement on the thermal conductivity and mechanical properties of natural rubber composites $\uparrow$}

J. M. A. R. B. Jayasinghe, ${ }^{\text {ab }}$ R. T. De Silva, ${ }^{\text {b }}$ Rohini M. de Silva, (D) ${ }^{* a}$ K. M. Nalin de Silva, (D) ${ }^{\text {ab }}$ M. M. M. G. P. G. Mantilaka (D) ${ }^{\text {b }}$ and Vinod Asantha Silva ${ }^{c d}$

Thermal conductivity of natural rubber (NR) was enhanced by incorporating novel conductive hybrid nanofillers, namely polyaniline grafted carbon black (PANI/CB) nanoparticles and carbon black nanoparticles linked with carbon microfiber (CF/CB) composites. The PANI/CB hybrid fillers were synthesized using an in situ method, where aniline monomers were initially adsorbed onto carbon black spherical domains and, afterwards, it was polymerized in the presence of an oxidizer. Final rubber composites were prepared through melt mixing, where PANI/CB and CF/CB filler loading was kept at 40 parts per hundred of rubber (phr). The thermal conductivity values of the rubber composites with $C F / C B$ (20:20) and PANI/CB $(20: 20)$ yield were $0.45 \mathrm{~W} \mathrm{~m}^{-1} \mathrm{~K}^{-1}$ and $0.31 \mathrm{~W} \mathrm{~m}^{-1} \mathrm{~K}^{-1}$, respectively and the thermal conductivity improved significantly compared to the control $\left(0.25 \mathrm{~W} \mathrm{~m}^{-1} \mathrm{~K}^{-1}\right)$ sample. The higher thermal conductivity values of CF/CB and PANI/CB incorporated composites suggest that the generated networked structure of $\mathrm{CF}$ and PANI nanofibers with $\mathrm{CB}$ nanoparticles has immensely contributed to enhancing the heat dissipation compared to that of the neat $C B$ rubber composite. Scanning electron micrographs (SEM) confirmed the attachment of the synthesized PANI onto the spherical CB nanoparticles and interconnected morphology of CF/CB and PANI/CB hybrid fillers. The synthesized PANI/CB hybrid filler was further characterized using Fourier-transform infrared (FTIR) spectroscopy to evaluate the chemical properties. Furthermore, thermogravimetric analysis revealed the higher thermal stability of CF/CB $(20: 20)$ and PANI/CB $(20: 20)$ composites compared to the control. Moreover, the addition of CF/CB $(20: 20)$ and PANI/CB $(20: 20)$ improved the mechanical properties such as ultimate tensile strength, modulus at break, resilience and abrasion resistance significantly and well above the minimum required standard mechanical parameters in the tyre industry. These reinforced composites show great potential to be used as heat dissipating rubber composites in the tyre industry.

\section{Introduction}

In the modern era with the fourth industrial revolution, rubber has invaded a vast number of engineering applications ${ }^{\mathbf{1 - 4}}$ due to its remarkable properties such as elasticity, shock absorption, thermal insulation and electrical insulation. Nevertheless, the thermal insulating property could be a drawback in certain applications such as tyres, conveyor belts and thermal pads.

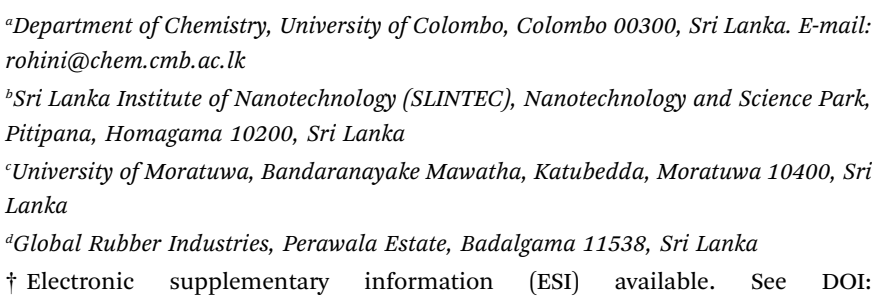
10.1039/c8ra08543a
Hence, the thermal conductivity has become a crucial factor in developing durable industrial goods. ${ }^{5}$ In order to achieve desired physical properties, rubber is always combined with other additives such as fillers, protective agents, processing aids and curative. As a result, the virgin elastomer matrix becomes a complex $3 \mathrm{D}$ structure to accomplish the required properties in desired applications. In conventional applications of rubber tyres, the matrix of the each article always tends to undergo relaxation followed by compression (flexing) or friction with the secondary surface. In the case of flexing, the polymer network and its embedded particles would collide each other and as a result, internal heat is generated. ${ }^{6}$ In addition, heat is also generated due to friction and that heat arises at the surface of each article. ${ }^{6}$ Generated heat via friction and flexing can be reduced by decreasing the heat generation or dissipation of generated heat efficiently through the composite. This can greatly contribute to reducing the mechanical failures in actual usage. 
Generally, neat rubber is considered as an insulator with having $0.1-0.2 \mathrm{~W} \mathrm{~m}^{-1} \mathrm{~K}^{-1}$ thermal conductivity. ${ }^{7,8}$ As this value is not sufficient to dissipate heat efficiently to the environment, overall thermal conductivity is increased by adding proper filling material for the development of long lasting products for temperature sensitive applications. Smith et al. have studied the thermal conductivity of carbon black (CB), processed wood fiber, expanded vermiculite and granulated cork as filling materials, and CB deemed to have a low conductivity value $\left(0.182 \mathrm{~W} \mathrm{~m}^{-1} \mathrm{~K}^{-1}\right)$ compared to expanded vermiculite mineral $\left(0.480 \mathrm{~W} \mathrm{~m}^{-1} \mathrm{~K}^{-1}\right) .{ }^{9}$ However, they have not investigated these as filling materials in other composite materials. In addition, the hybrid filler system to increase the thermal conductivity of epoxy based composites, ${ }^{\mathbf{1 0}}$ where, silicon carbide (SiC), boron nitride (BN), aluminum nitride ( $\mathrm{AlN}$ ) and wollastonite have been tested as filling materials for microelectronic packaging and combination of fibrous and spherical filler systems and have shown enhanced thermal conductivity (AlN/SiC $-2.25 \mathrm{~W}$ $\mathrm{m}^{-1} \mathrm{~K}^{-1}$ ) compared to single filler system (AlN $-2.14 \mathrm{~W} \mathrm{~m}^{-1}$ $\left.\mathrm{K}^{-1}\right) .{ }^{11} \mathrm{Sim}$ et al. have studied the incorporation of inorganic filler system having $\mathrm{Al}_{2} \mathrm{O}_{3}$ and $\mathrm{ZnO}$ in thermal pads to dissipate internal heat efficiently and reported that the thermal conductivity of $\mathrm{ZnO}$ filled silicon rubber $\left(0.2598 \mathrm{~W} \mathrm{~m}^{-1} \mathrm{~K}^{-1}\right)$ has increased compared to that of the $\mathrm{Al}_{2} \mathrm{O}_{3}$ filled silicon rubber composite $\left(0.2498 \mathrm{~W} \mathrm{~m}^{-1} \mathrm{~K}^{-1}\right)$. Furthermore, they have determined the percolation threshold for the filler system as $10 \%$ from its total volume and used theoretical models such as Maxwell-Eucken, Bruggeman and Cheng-Vochan to prove the dispersion of $\mathrm{Al}_{2} \mathrm{O}_{3}$ and $\mathrm{ZnO}$ as fillers in polymer matrix and continuous heat conductive path of the filler units. ${ }^{12}$ In industrial applications such as tyres, thermal conductivity of the material should not increase at the expense of the mechanical properties. In many studies, less attention have been paid to retain or enhance mechanical properties while improving the thermal conductivity with fillers. ${ }^{13-15}$ In general, heat transfer of solid-state materials are taken place by means of phonons, photons and electrons, but in most polymers, the free movement of electrons are not possible. ${ }^{\mathbf{1 6}}$ In polymers, heat is transferred as a result of crystal lattice vibration by means of phonons, where the total crystallinity of the polymer is proportionate to the heat conductivity of the polymer. For instance, natural rubber, a low crystalline polymer has an inferior thermal conductivity due to the phonon scattering. ${ }^{10}$ Such phonon scatterings are taking place due to the absence of connectivity within the polymer strands and resulting a low thermal conductivity. ${ }^{\mathbf{1 7}}$ The most convenient way to improve the thermal conductivity of inferior conductors such as natural rubber is by generating a conductive pathway in the polymer matrix. ${ }^{18}$ This pathway should be continuous and that can be achieved by incorporating large conductive filler particles into the polymer matrix. Although, incorporation of large fillers particles and high concentrations help to generate the conductive pathway, these lead to inferior mechanical properties due to the poor filler-matrix interaction and high stress concentrated areas around the large filler particles.

Therefore, in this study, networked composite system comprised of (i) polyaniline grafted carbon black (CB/PANI) and (ii) carbon fiber-carbon black (CF/CB) hybrid, was introduced to enhance heat dissipation while keeping higher mechanical strength of the rubber composite. PANI-CB was synthesized using a novel in situ method, where PANI strands grow on the spherical CB particles to interconnect the CB particles. In $\mathrm{CF} / \mathrm{CB}$ hybrid system, CF were expected to generate a network with spherical CB particles by linking one another to act coherently to enhance heat dissipation. The heat dissipation studies were carried out using thermal imaging and thermal conductivity of prepared rubber composites was measured using Lee's method. Mechanical properties of the composites were evaluated using tensile strength, tear strength and modulus. Fracture surface of the samples were identified using scanning electron microscope (SEM) to investigate the fracture mechanism. Furthermore, Fourier-transform infrared spectroscopy (FTIR) was used to characterization and the thermal stability was evaluated using thermogravimetric analysis (TGA). Rheological properties were studied using rheometer to determine the curing behavior of prepared rubber composites. The $\mathrm{CF} / \mathrm{CB}$ and $\mathrm{CB} / \mathrm{PANI}$ composites with enhanced mechanical and thermal properties can certainly be used for heat generating rubber-based application such as tyres.

\section{Experimental section}

\section{Materials and methods}

Aniline monomer (purity $\geq 99.5 \%$ ) was purchased from Merck. Ammonium persulfate (APS) (purity $\geq 99.99 \%$ ), absolute ethanol (purity $\geq 99.8 \%$ ) and hydrochloric acid ( $\mathrm{HCl})(37 \%)$ were brought from Sigma Aldrich USA. Other chemicals for preparation of rubber composite such as low PCA rubber processing oil (low polycyclic aromatic (PCA)), $N$-isopropyl- $N{ }^{\prime}-$ phenyl- $p$-phenylenediamine (IPPD), 2,2,4-trimethyl-1,2dihydroquinoline (TMQ), zinc oxide ( $\mathrm{ZnO})$ (99.5\%), stearic acid (SA), $N$-tert-butyl-benzothiazole sulfonamide (TBBS), tetramethyl thiuram monosulfide (TMTM), ( $N$-(cyclohexylthio) phthalimide (CTP) pre vulcanization inhibitor (PVI) from Nocil limited, India) and insoluble sulphur were industrial grade and used as received. Carbon black (CB) (N 375 grade from Phillips Carbon Black Limited india) and carbon fiber (CF) (Carbiso ${ }^{\mathrm{TM}}$ MF80, diameter $7 \mu \mathrm{m}$ and length $80 \mu \mathrm{m}$ from ELG Carbon Fibre Ltd.) were used as filler additives. Natural rubber (NR) (Vietnam RSS III) and butyl rubber (BR-cis 132) were used as matrix for the preparation of rubber composites.

\section{Preparation of polyaniline (PANI) grafted carbon black (CB/ PANI) composites}

The preparation of $\mathrm{CB} / \mathrm{PANI}$ has been reported previously ${ }^{\mathbf{1 9}}$ and the modified procedure was used in this study. CB was mechanically stirred at $0{ }^{\circ} \mathrm{C}$ for 2 hours in $1 \mathrm{M} \mathrm{HCl}$ and $1 \mathrm{M}$ aniline precursor medium. While stirring, 0.5 M APS in $1 \mathrm{M}$ $\mathrm{HCl}$ (both at $0{ }^{\circ} \mathrm{C}$ ) was added for a period of $30 \mathrm{~min}$ and stirred for another 2 hours to chemically polymerize PANI on CB particles. Monomer (aniline) to oxidized (APS) ratio was maintained at $(2: 1)$ for each synthesis and by considering the $50 \%$ yield of PANI, and two composites were prepared as CB/ 
PANI (50:50 w/w\%) and CB/PANI (75:25 w/w\%). For comparison purposes, neat polyaniline sample was prepared following the same synthesis procedure without adding any carbon black. Hereafter, CB/PANI (50:50 w/w\%) and CB/PANI (75:25 w/w\%) are referred as CB/PANI (20:20 phr) and CB/ PANI (30: $10 \mathrm{phr})$, respectively.

\section{Preparation of rubber composites}

The rubber composites were prepared through solid mixing by using internal mixture (HAAKE Polylan OS RheoDrive 7, Thermo SCIENTIFIC) and the resulted rubber mixture was sheeted by two roll mill. For the preparation of rubber composite, initially NR and BR were blended in the internal mixture followed by adding filler, processing aids, protective agents and curing agent within specific time intervals. Detailed mixing cycle is given in the Table S1. $\dagger$ All the formulations were processed at $80{ }^{\circ} \mathrm{C}$ and the rotor speed was $80 \mathrm{rpm}$ throughout the mixing process. The total rubber (polymer) content was 100 $\mathrm{phr}$ in each formulation and the total filler amount was $40 \mathrm{phr}$ except the control $\mathrm{CF} / \mathrm{CB}(0: 0)$. In other $\mathrm{CF} / \mathrm{CB}$ formulations, $\mathrm{CB}$ and $\mathrm{CF}$ were changed as $\mathrm{CF} / \mathrm{CB}(40: 0), \mathrm{CF} / \mathrm{CB}(30: 10), \mathrm{CF} /$ $\mathrm{CB}(20: 20), \mathrm{CF} / \mathrm{CB}(10: 30)$ and $\mathrm{CF} / \mathrm{CB}(0: 40)$ in phr. In the case of $\mathrm{CB} / \mathrm{PANI}$ formulations, $\mathrm{CB}$ to PANI ratio was $\mathrm{CB} / \mathrm{PANI}$ $(20: 20)$ and $\mathrm{CB} / \mathrm{PANI}(30: 10)$ in phr. The samples were cured in hydraulic heating press at $150{ }^{\circ} \mathrm{C}$ to prepare $(2 \times 100 \times$ 100) $\mathrm{mm}$ sheets and $t_{90}$ value of each sample was considered as an optimum curing time. Detailed information about the formulations are given in Table S2. $\dagger$

\section{Chemical properties}

Fourier transform infrared (FTIR) spectroscopy (Bruker Vertex 80) was conducted to identify the characteristic peaks of in situ polymerized $\mathrm{CB} / \mathrm{PANI}$ composite compared to neat PANI polymer and $\mathrm{CF} / \mathrm{CB}, \mathrm{CB} / \mathrm{PANI}$ rubber composites. The scan was operated within $500 \mathrm{~cm}^{-1}$ to $3000 \mathrm{~cm}^{-1}$ with 32 scans per measurement at $0.4 \mathrm{~cm}^{-1}$ resolution.

\section{Morphological analysis}

The surface morphology of neat PANI, neat CB/PANI composite, $\mathrm{CF} / \mathrm{CB}$ rubber composites and $\mathrm{CB} / \mathrm{PANI}$ rubber composites were carried out by field-emission scanning electron microscope (SEM) (Hitachi SU6600). The images were recorded in the secondary electron mode and the sample was coated with gold to prevent the electrostatic charging during the observation. All samples were kept in a desiccator prior to imaging.

\section{Thermal properties}

Conductivity measurements. Thermal conductivity of all formulations were measured by using Lees' disc method to obtain the best thermal conductive composition. In summery; specimen was sandwiched between two copper discs and constant heat (at $100{ }^{\circ} \mathrm{C}$ ) was supplied through lower disc to upper disc. After reaching the saturation temperature $\left(T_{\mathrm{s}}\right)$, the values of both discs were recorded. Thereafter, the upper disc was separately heated (about $10^{\circ} \mathrm{C}$ ) than its $T_{\mathrm{s}}$ and kept to cool and the temperature was recorded within 1 min intervals to obtain the cooling rate $\left(H_{\mathrm{c}}\right)$ at $T_{\mathrm{s}}$. Finally, using $H_{\mathrm{c}}$ at $T_{\mathrm{s}}$, the thermal conductivity value was obtained. Moreover, the ambient temperature and humidity level of experiment were maintained at $25{ }^{\circ} \mathrm{C}$ and $65 \%$ respectively.

Thermal imaging analysis. Infrared camera (IRC) (FLIR i7 Infrared Thermal Imaging Camera 60101-0301) was conducted to measure the surface temperature of rubber composites. Button-shaped samples (diameter of $20 \mathrm{~mm}$ and thickness of 10 $\mathrm{mm}$ ) were prepared using specific molds prior to thermal imaging. The objects were heated up to $105{ }^{\circ} \mathrm{C}$ using a hotplate and kept another $5 \mathrm{~min}$ to saturate the temperature. Then it was kept on a thermal insulating surface to dissipate heat through the air floor of surrounding (convection). While cooling down the object, its' surface temperature was measured using IRC within 1 minute time intervals for 18 minutes. This experimental procedure was triplicated for each formulation and the average was considered for further calculations as well as for graphical illustration of temperature $v s$. time plots.

\section{Rheological properties}

Oscillating Disk Rheometer (EKTRON EKT2000 Rotorless Rheometer) (ASTM D2084/D5289) was used to evaluate the rheological properties of each sample. Prior to implement the test, upper and lower dies' temperature was set to $150{ }^{\circ} \mathrm{C}$ and arc angle at $0.5^{\circ}$. Rheograph (torque $v s$. time) for each sample was obtained to evaluate minimum torque $\left(S_{1}\right)$, maximum torque $\left(S_{2}\right)$, scorch time $t_{2}$ and optimum curing time $\left(t_{90}\right)$.

\section{Physical properties}

Tensile and tearing properties. Tensile testing machine (Instron Model 3365) was utilized to evaluate the ultimate tensile stress, modulus at break (elastic modulus) (ASTM D412) and normal tear strength (ASTM D624) for each sample. Thickness of each sample were measured using digital micrometer screw-gauge (Mitutoyo, $0.001 \mathrm{~mm}$ resolution) prior to begin the test and the strain rate was set to $500 \mathrm{~mm} \mathrm{~min}^{-1}$ according to ASTM D412 standard.

Abrasion test. Rotary Drum Abrasion Tester (Hung Tа ${ }^{\mathrm{TM}}$ Rotary Drum Abrasion Tester Model HT8621B) was conducted to measure the abrasion of each sample. The rotor speed was $40 \mathrm{rpm}$ and load on the specimen was 500 grams. The specimen was fixed at the holder without rotation and it was abrade on abrasive media (425 $\mu \mathrm{m}$ \# 40 Grit) according to ASTM D5963 standard.

Resilience test. Rubber Rebound Resilience Elasticity Tester (Hefei Fanyuan Instrument Co. ltd) was conducted to measure the rebound resiliency of each sample as a percentage value according to the ASTM D2632-01.

\section{Results and discussion}

\section{Characterization of in situ synthesis CB/PANI composite}

The molecular structures of neat PANI and CB/PANI rubber composites were characterized by means of FTIR spectroscopy and SEM imaging. The PANI grafted CB samples were prepared 


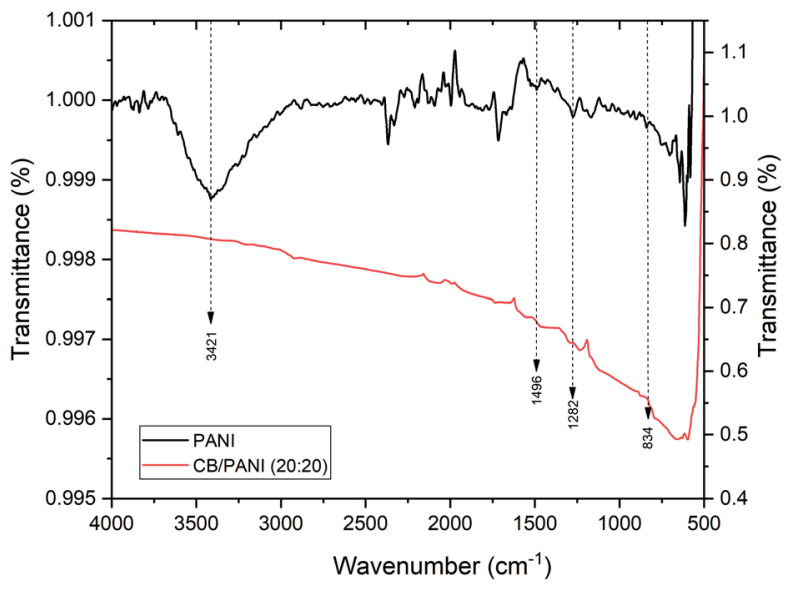

Fig. 1 FTIR spectra of neat PANI and CB/PANI (20:20) composite.

to obtain an interconnectivity among spherical CB particles. Herein, the aniline monomers are adsorbed on to CB spheres initially by means of physical interaction (van der Walls') while string at $\sim 0{ }^{\circ} \mathrm{C}$. Afterwards, the adsorbed monomers were polymerized through radical polymerization by adding APS as an oxidant in the present of $\mathrm{HCl}$ as a dopant. According to the FTIR spectra of neat PANI (Fig. 1(a)), the characteristic absorption band at $1165 \mathrm{~cm}^{-1}$ ascribes to the aromatic in plane bending vibration mode of $\mathrm{C}-\mathrm{H}$ bond. The nature of the peak was broadened and that reveals the degree of delocalization of electrons on PANI polymer. ${ }^{20}$ At the CB/PANI $(20: 20)$ (Fig. 1(b)) that peak was more broadened and less intense compared to the neat PANI spectra. It could be due to the higher physical interaction of aniline monomer with $\mathrm{CB}$ nano-sphere and the delocalization of electron cloud of conductive PANI through CB nano-spheres. Furthermore, other main functional groups of PANI such as C-N stretching vibration $\left(1282 \mathrm{~cm}^{-1}\right), \mathrm{N}-\mathrm{B}-\mathrm{N}(\mathrm{B}=$ benzenoid unit) $\left(1496 \mathrm{~cm}^{-1}\right)$, C-H out of plain bond vibration $\left(834 \mathrm{~cm}^{-1}\right)$ and $\mathrm{N}-\mathrm{H}$ bonds stretching vibration $\left(3421 \mathrm{~cm}^{-1}\right)$ were observed in $\mathrm{CB} / \mathrm{PANI}$ composites and that conforms the polymer attachment to the $\mathrm{CB}$ particles. Moreover, the corresponding peak for $\mathrm{N}-\mathrm{H}$ stretching vibration mode was disappeared in $\mathrm{CB} / \mathrm{PANI}$ spectra and that could be due to the strong adsorption of polyaniline on CB particles. ${ }^{20}$

\section{Morphological properties}

The surface morphology of the composites were examined by scanning electron microscope to determine the expected networked-structure. Fig. 2(a) shows the spherical nature of $\mathrm{CB}$ particles without any interconnected web structure. The particle size is $<100 \mathrm{~nm}$ and aggregates were formed to reduce higher surface energy of individual particles. The prepared CB/PANI composite depicted in Fig. 2(b) clearly shows the interconnection of $\mathrm{CB}$ particles (arrow a) using an extended network structure of PANI linkers (arrow b). These bridges (PANI linkers) correspond to the heat transfer between $\mathrm{CB}$ domains. Additionally, the fractured surface of final rubber composites of $\mathrm{CB} /$ PANI illustrated in Fig. 2(c) and (d) and the formation of networked PANI-structure even after mixing with the rubber composite.
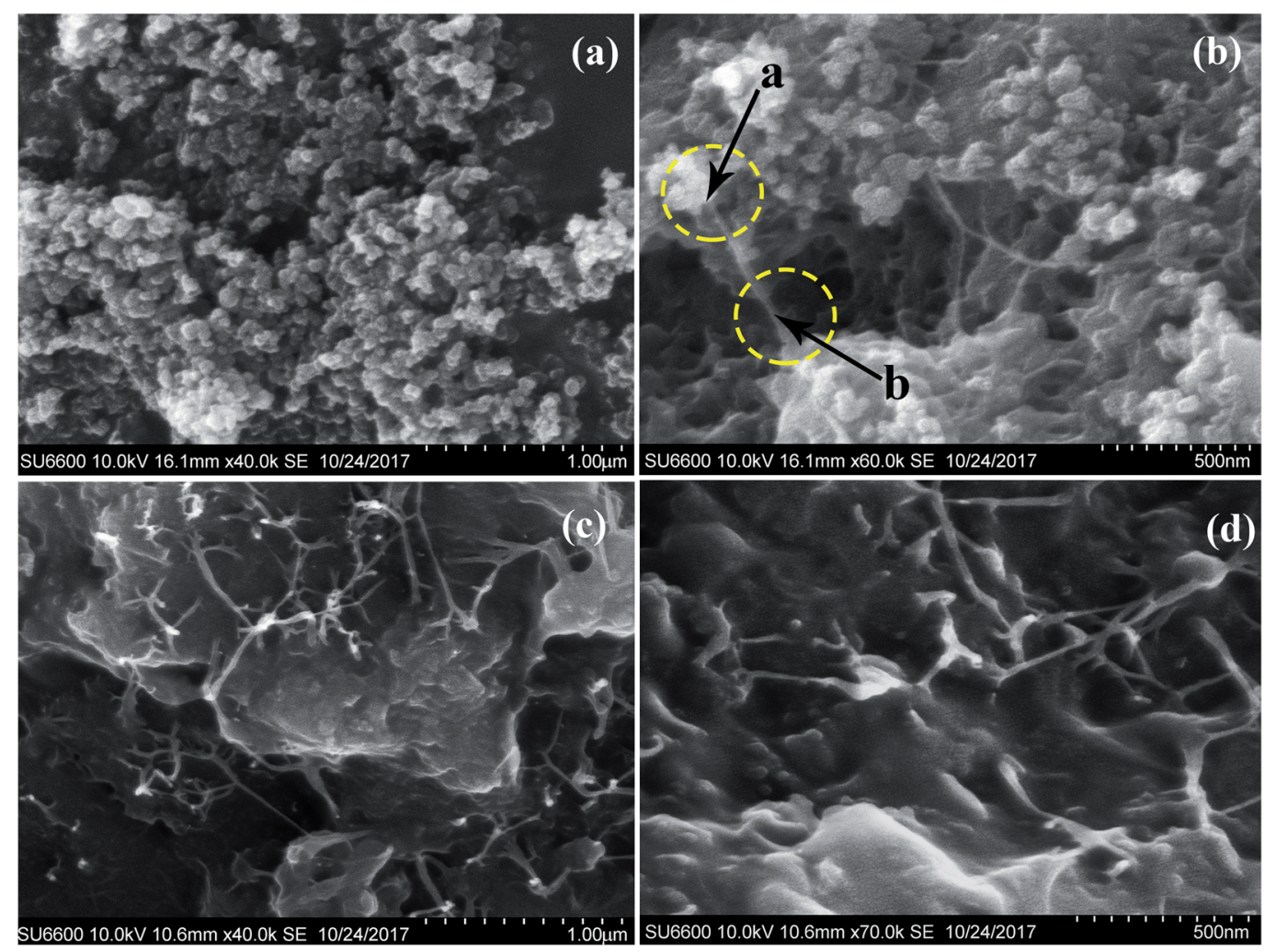

Fig. 2 Scanning electron microscope images of (a) neat CB (b) neat CB/PANI composite (c) and (d) CB/PANI rubber composite. 

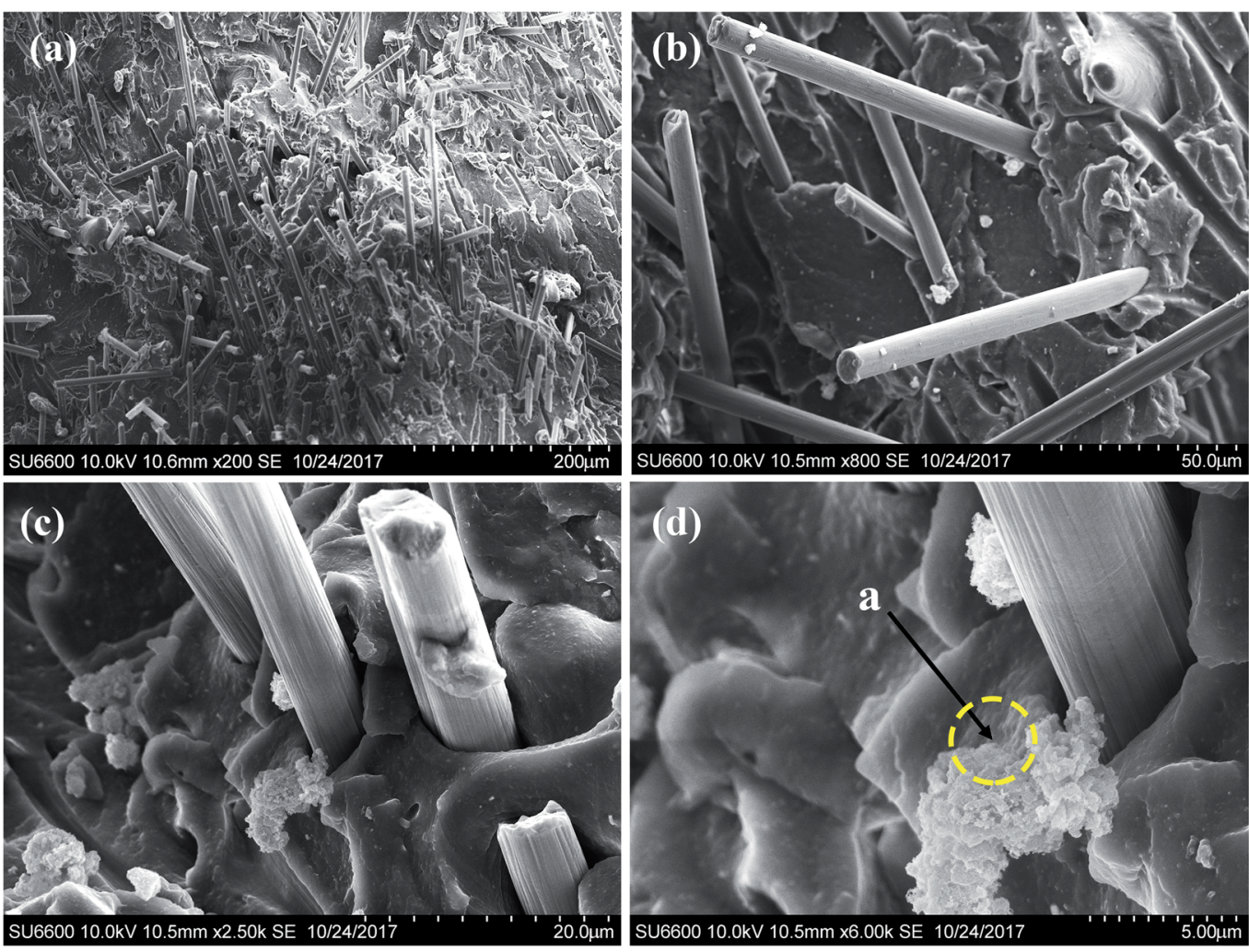

Fig. 3 Scanning electron microscope (SEM) image of fractured surface of CF/CB composites

Furthermore, the fractured surface of artificially generated $\mathrm{CF} / \mathrm{CB}$ thermal conductive network is illustrated in Fig. 3. According to the (Fig. 3(a) and (b)), carbon fibers penetrate the rubber matrix and at the higher magnification (Fig. 3(a) and (b)) it is clear that the CF are connected with CB particles (arrow a), generating a networked structure as expected.

\section{Thermal properties}

The heat dissipation of prepared composites was evaluated using a thermal imaging technique and the plot of specific temperature at different time intervals (cooling curves) is shown in Fig. 4. The cooling curves of prepared rubber composites with $\mathrm{CB} / \mathrm{PANI}$ and $\mathrm{CF} / \mathrm{CB}$ exhibit superior heat dissipation compared to that of the control sample $(\mathrm{CF} / \mathrm{CB}(0: 0))$. For instance, $\mathrm{CF} / \mathrm{CB}$ $(0: 0), \mathrm{CB} / \mathrm{CF}(20: 20)$ and $\mathrm{CB} / \mathrm{PANI}(20: 20)$ reach to a predefined temperature $\left(45^{\circ} \mathrm{C}\right)$ within $9.8,6.8$ and 7.75 minutes, respectively. For comparison purposes, the slope at $45{ }^{\circ} \mathrm{C}$ was obtained to determine the rate of heat dissipation $\left(R_{\mathrm{H}}\right)$ (Fig. $5(\mathrm{a})) . R_{\mathrm{H}}$ value of composites with $\mathrm{CB} / \mathrm{PANI}$ and $\mathrm{CF} / \mathrm{CB}$ increases drastically compared to the control sample. Moreover, the thermal conductivity values of $\mathrm{CF} / \mathrm{CB}(0: 0), \mathrm{CB} / \mathrm{CF}$ $(20: 20)$ and $\mathrm{CB} / \mathrm{PANI}(20: 20)$ were $0.25 \mathrm{~W} \mathrm{~m}^{-1} \mathrm{~K}^{-1}, 0.45 \mathrm{~W}$ $\mathrm{m}^{-1} \mathrm{~K}^{-1}$ and $0.31 \mathrm{~W} \mathrm{~m}^{-1} \mathrm{~K}^{-1}$ respectively (Fig. $5(\mathrm{~b})$ ), and which are in agreement with the $R_{\mathrm{H}}$ values of the composites (Fig. 5(a)). According to the thermal conductivity values of $\mathrm{CF} /$ CB composites, the highest value $\left(0.45 \mathrm{~W} \mathrm{~m}^{-1} \mathrm{~K}^{-1}\right)$ was obtained in $\mathrm{CF} / \mathrm{CB}(20: 20)$ composite compared to other composites. This could be due to more ordered and coherent connectivity of CF among CB particles in contrast to higher CF loading ( $\mathrm{CF} / \mathrm{CB} 30: 10)$. Reduction of thermal conductivity at higher CF loading can be attributed to lesser number of unidirectional alignment of the fibers compared to the direction of heat flow as observed in earlier reports for liquid crystalline polymer. It is expected to obtain high thermal conductivity at higher CF loading due to good conductivity. However, at the higher fiber loading, the unidirectional alignment of the fibers could be lesser compared to the direction of heat flow. As a result, the geometric mean of thermal conductivity of the composite can be lower at higher fiber loadings. ${ }^{16}$ Similar to this idea, Wong et al. has studied the thermal

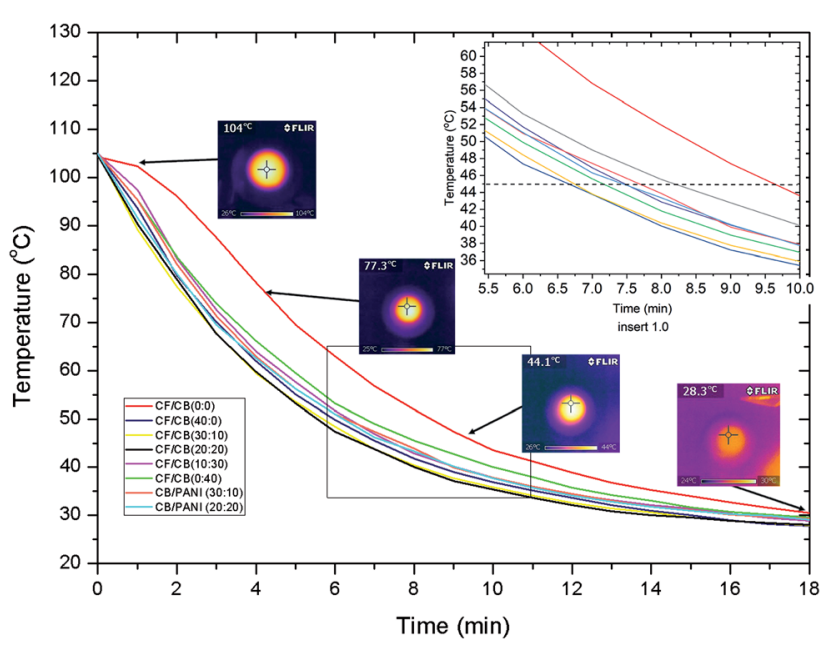

Fig. 4 Heat dissipation data of thermal imaging analysis. 


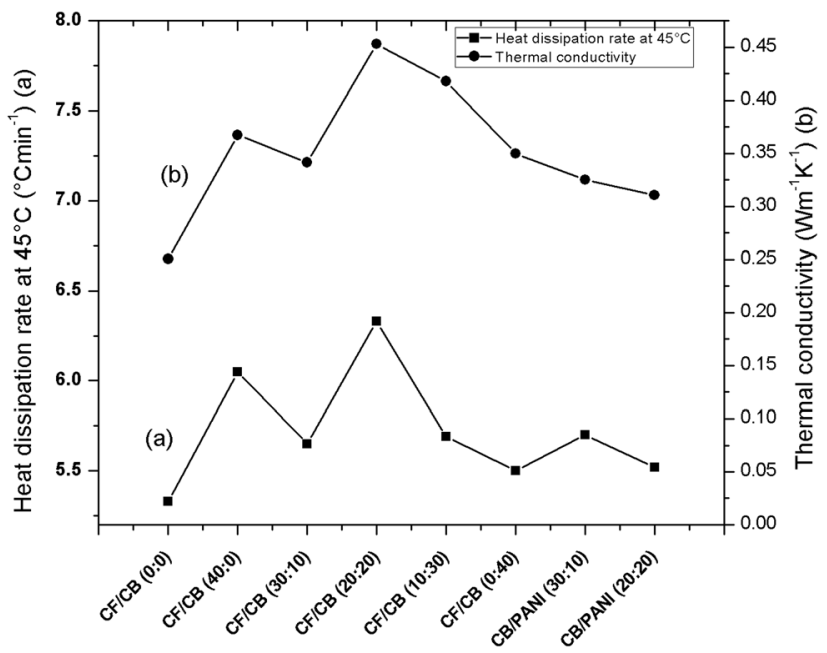

Fig. 5 The plot of (a) heat dissipation rate at $45^{\circ} \mathrm{C}$ and (b) thermal conductivity of the composites.

conductivity of liquid crystalline polymer (LCP) filled CB composites and reported that the molecular alignment of LCP matrix is responsible for the thermal conductivity of the composite. ${ }^{21}$ In $\mathrm{CB} / \mathrm{PANI}$ composites, significant improvement of thermal conductivity was achieved compared to the control sample. For instant, the thermal conductivity value of PANI at $10 \mathrm{phr}$ loading was higher $\left(0.32 \mathrm{~W} \mathrm{~m}^{-1} \mathrm{~K}^{-1}\right)$ than tha $t$ of $20 \mathrm{phr}$ $\left(0.31 \mathrm{~W} \mathrm{~m}^{-1} \mathrm{~K}^{-1}\right)$ loading. This slight difference could be due to well interconnect structure of CB and PANI, which was evident in morphological properties (Fig. 2).

The thermal degradation of control (CF/CB $(0: 0))$, CB/PANI $(20: 20)$ and $\mathrm{CF} / \mathrm{CB}(20: 20)$ composites were investigated by thermogravimetric analysis (Fig. 6). The thermal degradation of control was started at low temperature compared to other two samples and $25 \%$ of its initial weight was lost around $375{ }^{\circ} \mathrm{C}$ and the same weight loss of $\mathrm{CB} / \mathrm{PANI}(20: 20)$ and $\mathrm{CF} / \mathrm{CB}$ $(20: 20)$ was occurred around $400{ }^{\circ} \mathrm{C}$. Moreover, even at $500{ }^{\circ} \mathrm{C}$ the thermal stability of $\mathrm{CF} / \mathrm{CB}(20: 20)$ and $\mathrm{CB} / \mathrm{PANI}$

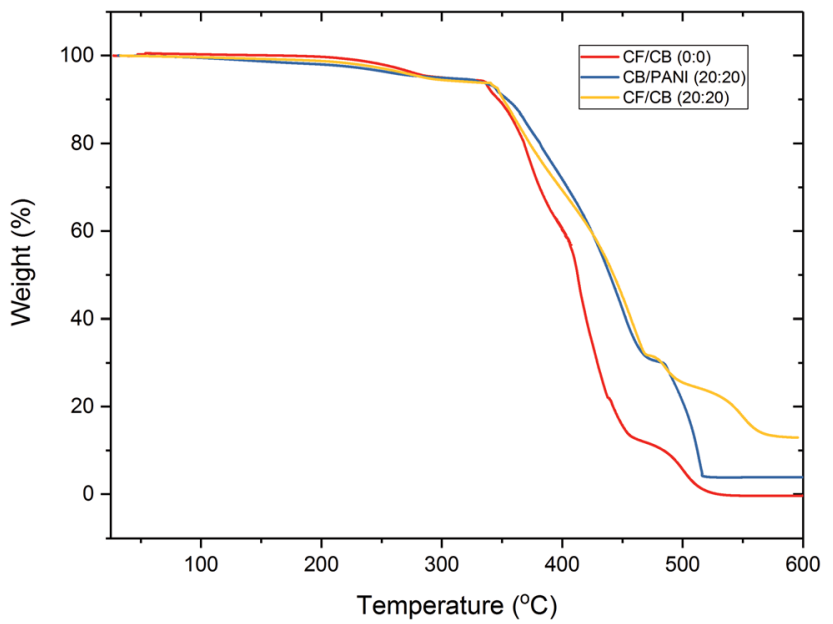

Fig. 6 TG thermograms of CB/PANI $(20: 20)$ and CB/PANI $(20: 20)$ compared with control (CF/CB $(0: 0))$.
(20:20) were retained considerably compared to control. For instant, at $500{ }^{\circ} \mathrm{C}$, the control was almost degraded and $25 \%$ weight was remained of CF/CB $(20: 20)$ and $\mathrm{CB} / \mathrm{PANI}(20: 20)$ composites. Furthermore, away from $500{ }^{\circ} \mathrm{C}$, the thermal stability of CB/PANI $(20: 20)$ was reduced gradually and even at that condition, the significant thermal stability of $\mathrm{CF} / \mathrm{CB}$ $(20: 20)$ was observed.

\section{Mechanical properties}

Mechanical properties, namely the normal tear strength, ultimate tensile strength and modulus at break are depicted in Fig. 7. As shown in Fig. 7(c) the ultimate tensile strength of the composites clearly reveals that the lower CF loaded composites are attained higher tensile properties than that of its higher $\mathrm{CF}$ loadings. Moreover, the modulus at break (Fig. 7(a)) and the normal tear strength (Fig. 7(b)) show a similar trend to the tensile strength of the composites. The highest values of tensile, modulus and tear strength were obtained at $\mathrm{CF} / \mathrm{CB}(0: 40)$ composite due to smaller size of $\mathrm{CB}(40-80 \mathrm{~nm})$ spherical particles. Conversely, micro-scaled dimensions of CF (diameter of $7 \mu \mathrm{m}$ with an aspect ratio of $1: 1700$ ) lead to inferior interfacial interaction with polymer and lower stress transfer form matrix to filler. ${ }^{14}$ Tensile properties of $\mathrm{CF} / \mathrm{CB}$ composites were reduced with the CF loading and this could be due to the lower degree of dispersion of $\mathrm{CF} / \mathrm{CB}$ filler with the polymer matrix or the mismatch of the ratio between $\mathrm{CF}$ and $\mathrm{CB}$ with the polymer matrix. Hence, compared to both mechanical and thermal properties, the $\mathrm{CF} / \mathrm{CB} 20: 20$ composite deemed to be the optimum composition. Furthermore, the mechanical properties of PANI/CB composites enhanced significantly compared to that of the control $(\mathrm{CF} / \mathrm{CB}(0: 0))$. However, at the synthesis process, the $\mathrm{CB}$ particles were aggregated and that can be clearly seen in SEM (Fig. 2(c)) studies. The size of the aggregates (micron level) could be a reason to these inferior mechanical properties of the composites at high PANI/CB loadings.

The rebound resilience, hardness and abrasion were evaluated and the results are depicted in Fig. 8. Rebound resilience

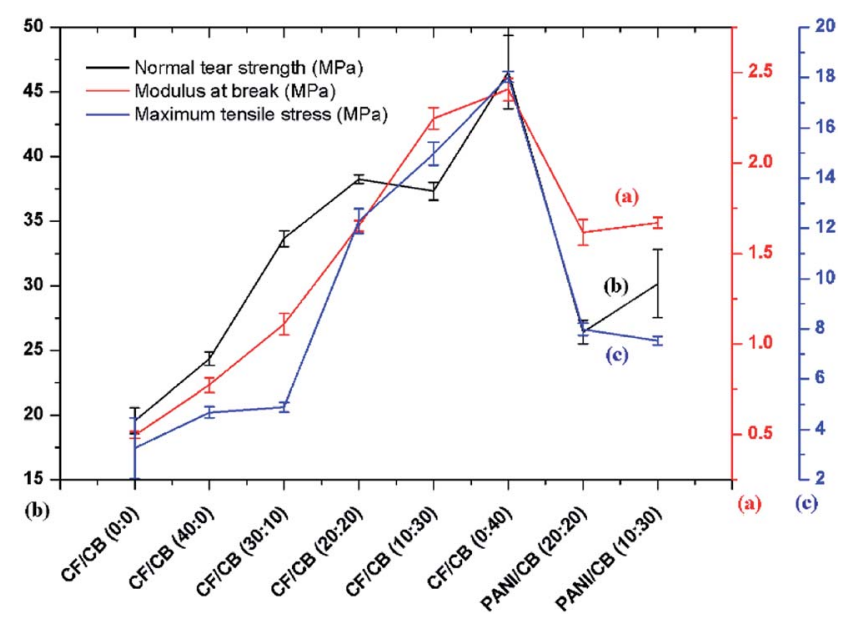

Fig. 7 Mechanical properties ((a) modulus at break (b) normal tear strength (c) maximum tensile strength) of the composites. 
(Fig. 8(b)) of the control sample (CF/CB (0:0)) showed the highest value compared to other samples. Moreover, rebound resilience value was reduced systematically when the CF loading increases. As an exception at $\mathrm{CF} / \mathrm{CB}(20: 20)$, rebound resilience value was increased significantly compared to other composites.

Typically, the heat generation of a composite is taken place due to restriction of polymer flexing and if the flexing process is reduced, as a result of it, rebound resilience reduces. Therefore, the higher rebound resilience of $\mathrm{CF} / \mathrm{CB}(20: 20)$ composite would lead to lower heat generation and it can be suggested to produce durable industrial applications.

Hardness (Fig. 8(a)) of the control sample is lower than other composites and the optimum value was obtained at CF $40 \mathrm{phr}$ loading. Thereafter, by reducing the $\mathrm{CF}$ loading in $\mathrm{CF} / \mathrm{CB}$ hybrid fillers of composites, the hardness decreased systematically. At PANI/CB composites hardness increased slightly. Carbon fibers are reported as high strength (modulus 350-450 $\mathrm{GPa}^{22}$ ) and light weight material ${ }^{23}$ than carbon black (modulus $10 \mathrm{GPa}^{24}$ ) particles. After blending, the fibrous and lightweight nature of CF have contributed to well pack within the rubber matrix and that could be a reasonable impact to increase the hardness of CF loaded composites. At PANI/CB composites, the fibrous nature of PANI polymer was revealed at SEM studies and that could be an involvement to slight increment of the hardness value. The abrasion loss of tested formulations are depicted in Fig. 7(c). The abrasion loss of the composites were systematically reduced with increasing the $\mathrm{CB}$ loading and highest abrasion value $\left(550.26 \mathrm{~mm}^{3}\right)$ was noticed in control. The neat CB composite (CF/CB $(0: 40))$ showed the highest abrasion resistance $\left(73.59 \mathrm{~mm}^{3}\right)$ which is a $647 \%$ reduction of abrasion compared to the control and that could be due to the lower size of the CB particles with uniform distribution. These improvements could be due to the better interfacial interaction between filler and matrix. In this case, polymer strands of NR would physically interact with CB particles. This was further confirmed with the FTIR data as shown in Fig. S1.† Moreover, at $20 \mathrm{phr}$ of

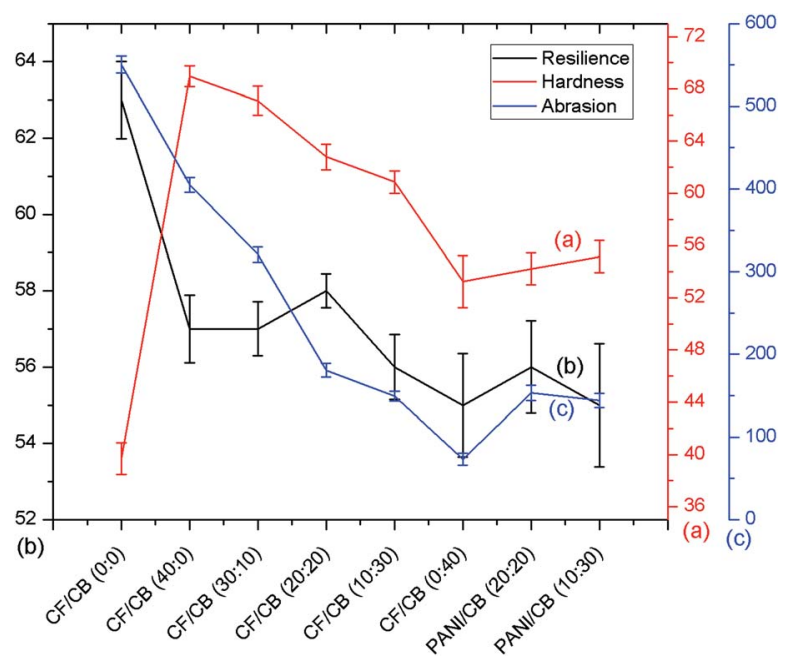

Fig. 8 Mechanical properties ((a) hardness (b) resilience (c) abrasion) of the composites.
CF loading, the abrasion loss was $180.65 \mathrm{~mm}^{-3}$ and it was reduced the abrasion by $204 \%$ compared to that of the control sample. Nevertheless, the abrasion was slightly increased in $\mathrm{CF} /$ CB $(20: 20)$ composite compared to $\mathrm{CF} / \mathrm{CB}(0: 40)$ and that increment of abrasion is anticipated as a usage of the micron size fibrous filler materials. Furthermore, the abrasion loss of PANI/CB composite was decreased by $259 \%$ compared to the control. Considerably, if the thermal conductivity is more important compared to other mechanical properties in certain application such as tyres, the attention should be given to formulate a composition with higher thermal conductive values. For instance, CF/CB $(20: 20)$ formulation satisfied the all the desired requirements what we expected and that will be more useful to develop a mechanically robust and more durable industrial applications.

\section{Cure characteristics}

Curing behavior of the prepared composites was measured in terms of scorch time $\left(t_{2}\right)$, optimum curing time $\left(t_{90}\right)$, minimum torque $\left(S_{1}\right)$, maximum torque $\left(S_{2}\right)$, maximum and minimum torque difference $(\Delta S)$, and the values are shown in Table 1 . The highest $t_{2}$ value $(9.16 \mathrm{~min})$ reckoned to be in $\mathrm{CF} / \mathrm{CB}(0: 0)$ and with the addition of fillers with $\mathrm{NR}$, the $t_{2}$ was significantly reduced. At $40 \mathrm{phr}$ total filler loading, $t_{2}$ value for filled composites were obtained around $5 \mathrm{~min}$ and the $\mathrm{CF} / \mathrm{CB}(0: 40)$ showed the minimum scorch time. Addition of the CF with the composites can be restricted to make sulphur linkages among the NR polymer chains due to its fibrous nature than that of adding neat $\mathrm{CB}$ as a filler during vulcanization. At CB/PANI filled composites the $t_{2}$ did not change appreciably compared to $\mathrm{CF} / \mathrm{CB}$ filled composites. Scorch safety is a main requirement for compound processability and keeping an optimum scorch time is crucial for molding application such as tyres. Optimum curing time of the control (16.29 $\mathrm{min})$ showed the highest value compared to other composites. At CF loaded composites the optimum curing time was around $12 \mathrm{~min}$ and it was $8.08 \mathrm{~min}$ for the neat $\mathrm{CB}$ composite $(\mathrm{CF} / \mathrm{CB}(0: 0))$. Moreover, the $\mathrm{CB} / \mathrm{PANI}$ composites showed optimum curing time around $5 \mathrm{~min}$. The $\Delta S$ was measured considering minimum $\left(S_{1}\right)$ and maximum $\left(S_{2}\right)$ torque values. The lowest $\Delta S$ was obtained in control sample and $40 \mathrm{phr}$ filler loaded samples that value was around $13 \mathrm{~N} \mathrm{~m}$ and at $\mathrm{CF} / \mathrm{CB}(20: 20)$ the torque value $(11.96 \mathrm{~N} \mathrm{~m})$ was slightly reduced. At $\mathrm{CB} / \mathrm{PANI}$ composites, the torque value was around $12 \mathrm{~N} \mathrm{~m}$. A significant difference in $\Delta S$ was not observed while changing $\mathrm{CF}$

Table 1 Cure characteristics of the compounds

\begin{tabular}{llrrrr}
\hline Formulation & $S_{1}(\mathrm{~N} \mathrm{~m})$ & $S_{2}(\mathrm{~N} \mathrm{~m})$ & $\Delta S(\mathrm{~N} \mathrm{~m})$ & $t_{2}(\mathrm{~min})$ & $t_{90}(\mathrm{~min})$ \\
\hline CF/CB $(0: 0)$ & 0.53 & 7.41 & 6.88 & 9.16 & 16.29 \\
CF/CB $(40: 0)$ & 0.62 & 13.67 & 13.05 & 5.30 & 12.15 \\
CF/CB $(30: 10)$ & 0.89 & 14.52 & 13.63 & 5.41 & 12.47 \\
CF/CB $(20: 20)$ & 0.75 & 12.71 & 11.96 & 5.53 & 12.02 \\
CF/CB $(10: 30)$ & 0.02 & 15.28 & 15.26 & 5.58 & 11.50 \\
CF/CB $(0: 40)$ & 1.25 & 14.74 & 13.49 & 4.17 & 8.08 \\
CB/PANI $(20: 20)$ & 0.82 & 13.51 & 12.69 & 5.21 & 10.41 \\
CB/PANI $(10: 30)$ & 0.71 & 12.65 & 11.94 & 5.25 & 10.21
\end{tabular}


and CB. Fillers containing compounds' torque value is considerably increased due to filler polymer interaction and restriction to movement of polymer chains when crosslinking taken place at vulcanization. Ismail et al. has reported similar observation in the study of bamboo fibers filled NR rubber composites. ${ }^{25}$

\section{Conclusion}

PANI grafted carbon black nano particles were successfully synthesized using an in situ method and PANI linkers among CB nano spheres were obtained. The CF was used at mixing stage to obtain an interconnected matrix of CB particles with CF. The thermal conductivity of the composites improved significantly by incorporating $\mathrm{CB} / \mathrm{PANI}$ and $\mathrm{CF} / \mathrm{CB}$. For instance, thermal conductivity of the rubber composites improved by $29 \%$ and $80 \%$ with the addition of CB/PANI $(20: 20)$ and CF/CB $(20: 20)$ compositions. These improvements could be attributed to the networked structure, which was obtained by introducing $\mathrm{CB} /$ PANI and CF/CB, and it was confirmed with SEM imaging. The addition of these hybrid fillers also led to significant improvements in mechanical properties. Mechanical properties were peaked at $\mathrm{CF} / \mathrm{CB}(0: 40)$ loading due to the lower size of the particles $(\sim 40 \mathrm{~nm})$ and well dispersion. Optimum mechanical properties of rubber composites with CB/PANI $(20: 20)$ yielded at 40 phr loading. For instance, tensile strength, normal tear strength and abrasion of the rubber composites reinforced with CB/PANI (20 : 20) improved by $145 \%, 35 \%$ and $259 \%$ respectively. $\mathrm{CB} / \mathrm{CF}$ and $\mathrm{CB} / \mathrm{PANI}$ reinforced rubber composites exhibited superior physico-chemical properties, which are well above the industrial standards, and certainly, those can be used as the components of heat dissipating industrial tyres.

\section{Conflicts of interest}

There are no conflicts to declare.

\section{Acknowledgements}

We would like to thank Global Rubber Industries Pvt. Ltd. (Badalgama, Srilanka) for funding the research and Sri Lanka Institute of Nanotechnology (SLINTEC) for providing facilities to carry out all the characterizations.

\section{References}

1 E. O. Ogunsona, M. Misra and A. K. Mohanty, Influence of Epoxidized Natural Rubber on the Phase Structure and Toughening Behavior of Biocarbon Reinforced Nylon 6 Biocomposites, RSC Adv., 2017, 7(15), 8727-8739.

2 S. H. Song, J. M. Kim, K. H. Park, D. J. Lee, O. S. Kwon, J. Kim, $\mathrm{H}$. Yoon and $\mathrm{X}$. Chen, High Performance Graphene Embedded Rubber Composites, RSC Adv., 2015, 5(99), 81707-81712.

3 R. Kaltseis, C. Keplinger, S. J. Adrian Koh, R. Baumgartner, Y. F. Goh, W. H. Ng, A. Kogler, A. Tröls, C. C. Foo, Z. Suo, et al., Natural Rubber for Sustainable High-Power Electrical Energy Generation, RSC Adv., 2014, 4(53), 27905-27913.
4 F. C. Cabrera, J. C. P. De Souza, A. E. Job and F. N. Crespilho, Natural-Rubber-Based Flexible Microfluidic Device, RSC Adv., 2014, 4(67), 35467-35475.

5 R. O. Hall, Rubber as an Engineering Material, Int. J. Mater. Eng. Appl., 1979, 1(5), 295-302.

6 K. K. Kar and A. K. Bhowmick, Hysteresis Loss in Filled Rubber Vulcanizates and Its Relationship with Heat Generation, J. Appl. Polym. Sci., 1997, 64(8), 1541-1555.

7 A. Das, K. W. Stöckelhuber, R. Jurk, M. Saphiannikova, J. Fritzsche, H. Lorenz, M. Klüppel and G. Heinrich, Modified and Unmodified Multiwalled Carbon Nanotubes in High Performance Solution-StyreneButadiene and Butadiene Rubber Blends, Polymer, 2008, 5276-5283.

8 C. Guo, L. Zhou and J. Lv, Effects of Expandable Graphite and Modified Ammonium Polyphosphate on the FlameRetardant and Mechanical Properties of Wood FlourPolypropylene Composites, Polym. Polym. Compos., 2013, 21(7), 449-456.

9 W. R. Smith and G. B. Wilkes, Thermal Conductivity of Carbon Blacks, Ind. Eng. Chem., 1944, 36(12), 1111-1112.

10 D. Kumlutaş, I. H. Tavman and M. Turhan Çoban, Thermal Conductivity of Particle Filled Polyethylene Composite Materials, Compos. Sci. Technol., 2003, 63(1), 113-117.

11 G. W. Lee, M. Park, J. Kim, J. I. Lee and H. G. Yoon, Enhanced Thermal Conductivity of Polymer Composites Filled with Hybrid Filler, Composites, Part A, 2006, 37(5), 727-734.

12 L. C. Sim, S. R. Ramanan, H. Ismail, K. N. Seetharamu and T. J. Goh, Thermal Characterization of $\mathrm{Al}_{2} \mathrm{O}_{3}$ and $\mathrm{ZnO}$ Reinforced Silicone Rubber as Thermal Pads for Heat Dissipation Purposes, Thermochim. Acta, 2005, 430(1-2), 155-165.

13 G. W. Lee, M. Park, J. Kim, J. I. Lee and H. G. Yoon, Enhanced Thermal Conductivity of Polymer Composites Filled with Hybrid Filler, Composites, Part A, 2006, 37(5), 727-734.

14 Y. Xu, D. D. L. Chung and C. Mroz, Thermally Conducting Aluminum Nitride Polymer-Matrix Composites, Composites, Part A, 2001, 32(12), 1749-1757.

15 Y. Agari and T. Uno, Thermal Conductivity of Polymer Filled with Carbon Materials: Effect of Conductive Particle Chains on Thermal Conductivity, J. Appl. Polym. Sci., 1985, 30(5), 2225-2235.

16 Z. Han and A. Fina, Thermal Conductivity of Carbon Nanotubes and Their Polymer Nanocomposites: A Review, Prog. Polym. Sci., 2011, 36(7), 914-944.

17 C. L. Choy, Thermal Conductivity of Polymers, Polymer, 1977, 18(10), 984-1004.

18 W. Zhou, S. Qi, C. Tu and H. Zhao, Novel Heat-Conductive Composite Silicone Rubber, J. Appl. Polym. Sci., 2007, 104(4), 2478-2483.

19 F. R. Simões, L. O. S. Bulhões and E. C. Pereira, Synthesis and Characterization of Conducting Composites of Polyaniline and Carbon Black with High Thermal Stability, Polimeros, 2009, 19(1), 54-57.

20 J. Li, X. Tang, H. Li, Y. Yan and Q. Zhang, Synthesis and Thermoelectric Properties of Hydrochloric Acid-Doped Polyaniline, Synth. Met., 2010, 160(11-12), 1153-1158. 
21 Y. W. Wong, K. L. Lo and F. G. Shin, Electrical and Thermal Properties of Composite of Liquid Crystalline Polymer Filled with Carbon Black, J. Appl. Polym. Sci., 2001, 82(6), 15491555.

22 M. Alberto, Introduction of Fibre-Reinforced Polymers Polymers and Composites: Concepts, Properties and Processes, in Fiber Reinforced Polymers - The Technology Applied for Concrete Repair, Intech, 2013.

23 S. Y. Fu, X. Q. Feng, B. Lauke and Y. W. Mai, Effects of Particle Size, Particle/Matrix Interface Adhesion and Particle Loading on Mechanical Properties of Particulate-
Polymer Composites, Composites, Part B, 2008, 39(6), 933961.

24 M. Qu, F. Deng, S. M. Kalkhoran, A. Gouldstone, A. Robisson and K. J. Van Vliet, Nanoscale Visualization and Multiscale Mechanical Implications of Bound Rubber Interphases in Rubber-Carbon Black Nanocomposites, Soft Matter, 2011, $7(3), 1066-1077$.

25 H. Ismail, S. Shuhelmy and M. R. Edyham, The Effects of a Silane Coupling Agent on Curing Characteristics and Mechanical Properties of Bamboo Fibre Filled Natural Rubber Composites, Eur. Polym. J., 2002, 38(1), 39-47. 